\title{
Thoracic Ganglioneuromas Resulting in Nonimmune Hydrops Fetalis
}

\author{
Paul Singh, MD ${ }^{1}$ Cristiano Jodicke, $\mathrm{MD}^{2}$ Tara Swanson, $\mathrm{MD}^{3}$ Dev Maulik, MD, PhD ${ }^{4,5,6}$
}

${ }^{1}$ Division of Maternal-Fetal Medicine, Department of Obstetrics and Gynecology, University of Missouri Kansas City School of Medicine, Kansas City, Missouri

2 Division of Maternal Fetal Medicine and Staff Physician, Department of Obstetrics and Gynecology, Children's Mercy Hospital, Fetal Health Center, University of Missouri Kansas City School of Medicine, Kansas City, Missouri

${ }^{3}$ Division of Pediatric Cardiology, Department of Pediatrics, Children's Mercy Hospital, University of Missouri Kansas City School of Medicine, Kansas City, Missouri

${ }^{4}$ Department of Obstetrics and Gynecology, UMKC School of

Medicine, Kansas City, Missouri

${ }^{5}$ Department of Obstetrics and Gynecology, Truman Medical Center, Kansas City, Missouri

${ }^{6}$ Department of Maternal Fetal Medicine, Children's Mercy Hospital, Kansas City, Missouri

Am J Perinatol Rep 2014;4:49-54.
Address for correspondence Paul Singh, MD, Department of Obstetrics and Gynecology, University of Missouri, Kansas City School of Medicine, 2301 Holmes Street, Kansas City, MO 64108 (e-mail: paulsingh49@yahoo.com).

\begin{abstract}
Keywords

- ganglioneuroma

- hydrops fetalis

- thoracic

- neuroblastoma
\end{abstract}

Ganglioneuromas are benign tumors that originate from the sympathetic trunk of the peripheral nervous system. They occur infrequently with an incidence of approximately one per one million. ${ }^{1}$ Ganglioneuromas develop from primordial neural crest cells which migrate from the mantle layer of the developing spinal cord to the ganglia of the sympathetic nervous system. ${ }^{2}$ They most frequently occur within the adrenal gland, although there are reports of posterior mediastinal, retroperitoneal, intracranial, retropharyngeal, and colonic lesions as well. ${ }^{2-10}$ Most often ganglioneuromas occur received

November 30, 2013 accepted after revision January 20, 2014 published online April 15, 2014
DOI http://dx.doi.org/ 10.1055/s-0034-1371751. ISSN 2157-6998.
Copyright $\odot 2014$ by Thieme Medical Publishers, Inc., 333 Seventh Avenue, New York, NY 10001, USA. Tel: +1(212) 584-4662.
License terms

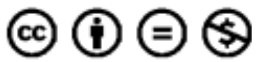




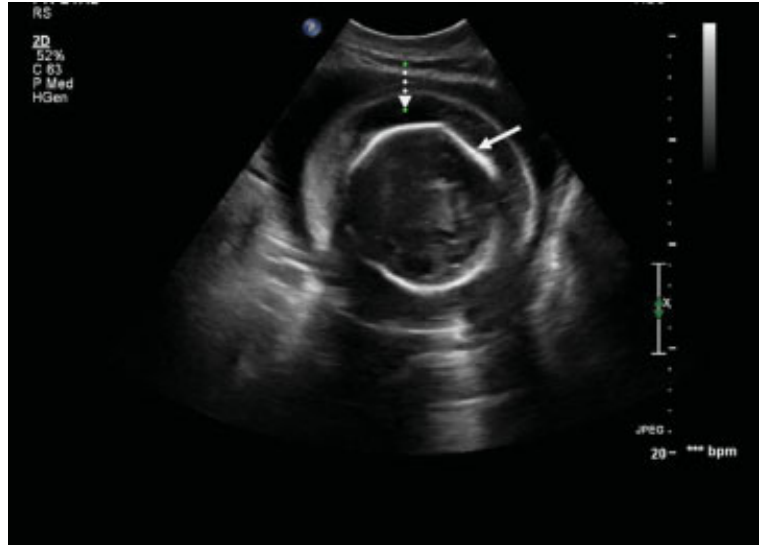

Fig.1 Fetal scalp edema. The solid arrow represents the fetal skull while the dotted arrow reflects accumulation of interstitial fluid within the fetal scalp.

sporadically; however, they have been associated with disorders such as neurofibromatosis type II and multiple endocrinologic neoplasia type II. ${ }^{11}$ We report a unique case of hydrops fetalis caused by compression of the distal ductus arteriosus and proximal descending aorta by thoracic ganglioneuromas.

\section{Case Report}

The patient is a 22-year-old Hispanic gravida 2 para 1 woman who was referred to our perinatal diagnostic center at 20 completed gestational weeks for an enlarged nuchal fold. Detailed fetal ultrasound revealed an appropriately grown fetus with diffuse skin and scalp edema, abdominal ascites, and bilateral pleural effusions (-Figs. 1-4). Fetal echocardiography demonstrated a distal aortic arch and ductal arch constriction ( - Fig. 5). The remainder of the cardiac anatomy, including biventricular sizes appeared normal. The middle cerebral artery peak systolic velocity was within the normal limits; thereby, reducing the likelihood of fetal anemia.



Fig. 2 Fetal skin edema. The dotted arrow represents accumulation of interstitial fluid within the skin overlying the entire fetal spine (solid arrow).

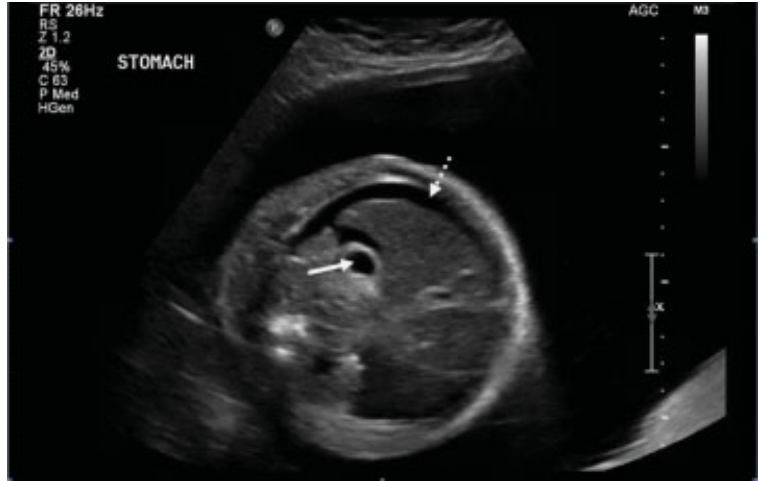

Fig. 3 Fetal abdominal ascites. Note the accumulation of fluid within the peritoneal cavity (dotted arrow) at the level of the fetal stomach (solid arrow).

Although a normal ductus venosus waveform was found, tricuspid regurgitation was identified, thus, suggesting a cardiac etiology for the hydrops. An amniocentesis was performed and revealed a normal female karyotype. The patient developed preterm premature rupture of membranes at 28 completed gestational weeks and received latency antibiotics, Group B streptococcus prophylaxis and steroids for fetal lung maturity. At 29 completed gestational weeks, a magnesium bolus was given for neuroprophylaxis and a cesarean delivery was undertaken for refractory labor and nonreassuring fetal status. The umbilical cord $\mathrm{pH}$ was 7.01 and the base deficit was 11.2. The 1 minute, 5 minutes, and 10 minutes Apgar scores were 1,1 , and 1 , respectively, and the birth weight was $2,730 \mathrm{~g}$. The neonate appeared markedly hydropic, with hypotonia, cyanosis, and no respiratory effort. Neonatal resuscitation was initiated with bag-masked ventilation, chest compressions, and epinephrine. Intubation was difficult due to a large amount of tracheal secretions and neck swelling. The maximal heart achieved was 50 beats per minute; however, the neonate demonstrated no further responsiveness to resuscitative efforts and the parents elected to initiate comfort care measures. The neonate

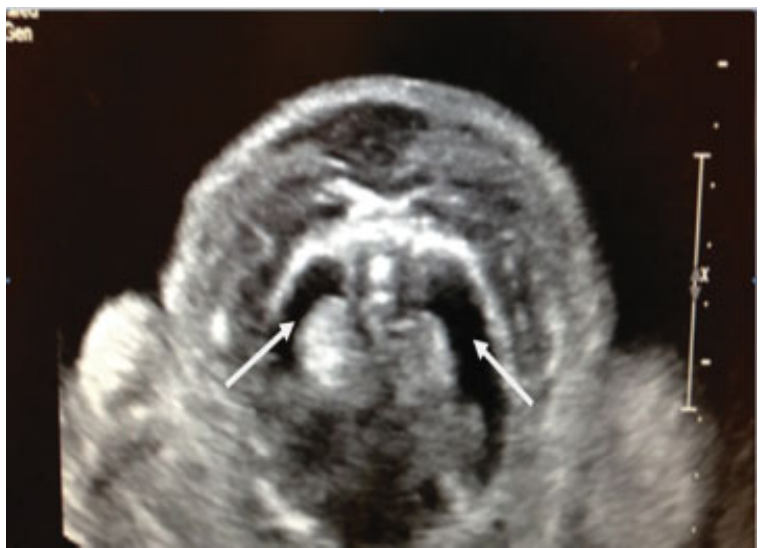

Fig. 4 Fetal pleural effusions. Note the appearance of bilateral pleural effusions (solid white arrows). 


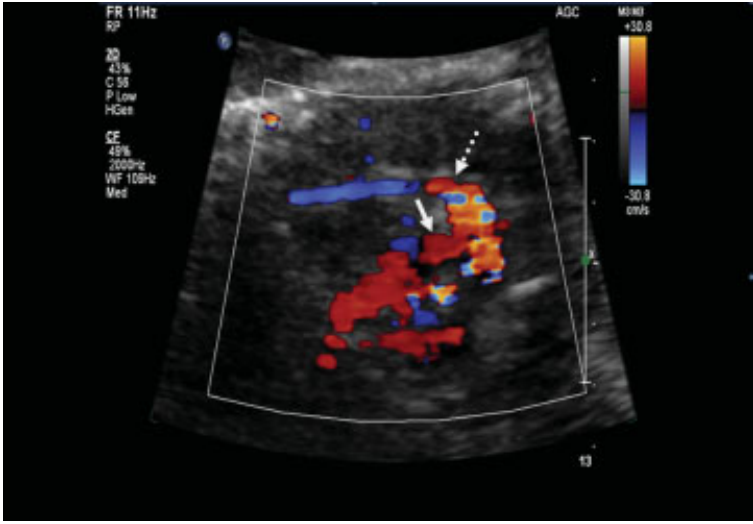

Fig. 5 Fetal aortic arch. The solid arrow represents the ascending aorta while the dotted arrow represents the aortic arch distal to the ductus arteriosus. Note the aliasing in the ductal arch reflecting turbulent blood flow as a result of external compression due to masseffect.

expired at 47 minutes of life. The macroscopic appearance of the neonate is shown in - Fig. $\mathbf{6}$. Autopsy revealed numerous solid, pale, and yellow thoracic masses immediately adjacent to the proximal descending aorta resulting in a significant mass effect. Histopathological examination of the tumors demonstrated nerve ganglion and spindle cells (-Fig. 7). Immunohistochemical staining for keratin, smooth muscle actin, vimentin, and desmin was negative. The ganglion cells and the spindle stromal surrounding cells showed immunoreactivity to protein $S-100$, while only the ganglion cells had affinity for neuron-specific enolase (NSE).

\section{Discussion}

Ganglioneuromas, along with neuroblastomas and ganglioneuroblastomas, are tumors of the sympathetic nervous system that arise from neuroectodermal cells derived from neural crest cells. While neuroblastomas and ganglioneuroblastomas tend to be more aggressive and occur in younger children, ganglioneuromas are highly differentiated benign

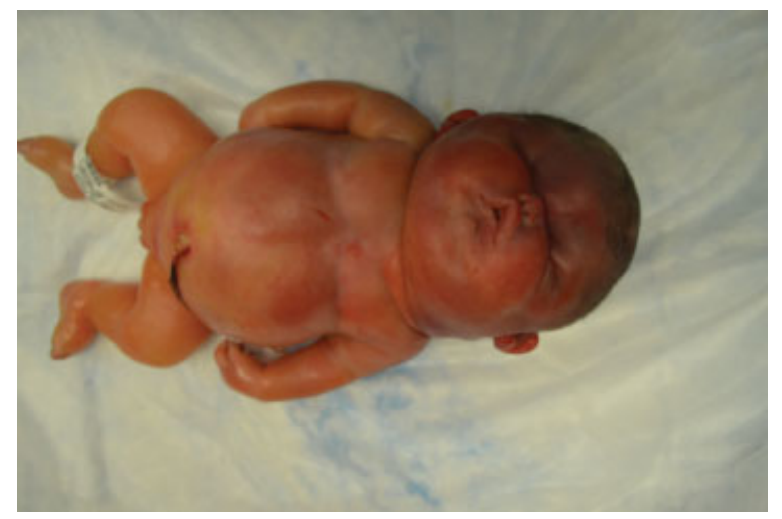

Fig. 6 Macroscopic appearance of the newborn. Note the edematous appearance of the head, trunk, and limbs resulting in a plethoric appearance.

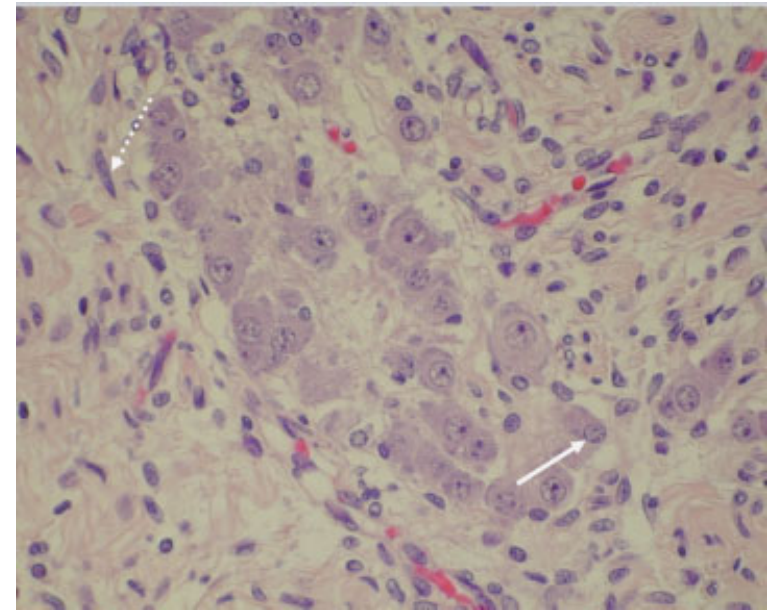

Fig. 7 Histological appearance of ganglioneuromas. Note the mixture of large ganglion cells (solid arrow) and spindle-shaped Schwann-like cells (dotted arrow). Hematoxylin and eosin stain $\times 400$ original magnification.

tumors and tend to occur in older pediatric patients. ${ }^{12}$ They may occur spontaneously or as a result of either chemotherapy or radiation therapy for neuroblastomas. ${ }^{13}$ In addition, ganglioneuromas may also occur as a result of necrosis of immature neuroblasts from either malignant primary or metastatic neuroblastomas. ${ }^{14}$ Generally, ganglioneuromas are multifocal in nature, although, they can be associated with other types of neurogenous neoplasms such as neuroblastoma and pheochromocytoma. ${ }^{14,15}$

Grossly, ganglioneuromas appear as encapsulated masses of firm consistency with a homogenous, solid, grayish white surface. Microscopically, the cells appear as spindle-shape containing numerous ganglion cells. Histologically, ganglioneuromas are divided into two subtypes. The mature subtype is characterized by the presence of fascicles composed of neuritic processes, Schwann cells, and perineural cells. The immature subtype, on the contrary, has a similar type of stroma but with ganglion cells of differing levels of maturation. ${ }^{14}$ Immunohistochemically, they are characterized by reactivity with S-100 and neuronal markers such as NSE and synaptophysin. ${ }^{16}$

Ganglioneuromas are typically slowly growing, benign tumors. Generally, they remain clinically silent until they reach large enough sizes and compress adjacent structures to cause adverse effects. Occasionally, ganglioneuromas may release peptides such as vasoactive intestinal peptides, somatostatins, neuropeptide $Y$, and catecholamines which may cause symptoms such as diarrhea, sweating, and hypertension. Indeed, Gentile et al described the development of hypertensive crisis during the resection of a catecholamine secreting ganglioneuroma. ${ }^{17}$ Although the majority of cases of ganglioneuromas are made by pathologic confirmation following surgical resection, fine needle aspiration cytology may be useful in the preoperative diagnosis of adrenal ganglioneuromas. ${ }^{11,18}$ Ganglioneuromas appear as well-circumscribed masses with a tendency to surround blood vessels on computed tomography and magnetic resonance imaging (MRI). They may also demonstrate high signal 
intensity on T2-weighted MRI. Nonetheless, in a study of 13 retroperitoneal ganglioneuromas, Ostertun et al reported that preoperative radiographic diagnosis is of limited value for ganglioneuromas. ${ }^{19}$

Hydrops fetalis is defined as abnormal accumulation of fluid in two or more fetal compartments, including ascites, pleural effusion, pericardial effusion, skin edema, polyhydramnios, and placentomegaly. The mechanism for the formation of fetal hydrops is an imbalance of interstitial fluid production and its subsequent lymphatic return. Before the introduction of immunoglobulin prophylaxis for at-risk mothers, immune-mediated hydrops predominated. Today, however, nonimmune hydrops (NIH) accounts for the majority of reported cases. NIH fetalis is a heterogeneous disorder with a variety of possible causes, including fetal arrhythmias, congenital infections, structural heart disease, $\alpha$-thalassemia, aneuploidy, sacrococcygeal teratomas, and twin-to-twin transfusion syndrome. Etiologies of NIH that are most commonly amenable to treatment include fetal tachyarrhythmias and congenital parvovirus infection. In a retrospective study reviewing all pregnancies complicated by NIH over 10 years, Santo et al reported a survival rate of only $48 \%{ }^{20}$

During fetal life the presence of the ductus venosus, foramen ovale, and ductus arteriosus allow the fetal heart to work as two parallel circulations. Blood rich in oxygen enters the fetus via the umbilical vein and passes through the liver via the ductus venosus and then enters the right atrium via the inferior vena cava. This oxygen-rich blood is directed across the foramen ovale by the Eustachian valve where it enters the left atrium, then to the left ventricle, into the aorta and then into the brachiocephalic vessels. Thus, the brain and upper extremities preferentially receive blood with the highest oxygen content. Oxygen-poor blood returning from the upper body via the superior vena cava also enters the right atrium, but this blood is preferentially directed into the right ventricle and then to the pulmonary artery. Most of this oxygen-poor blood bypasses the lungs by traveling through the ductus arteriosus to the distal aortic arch where it travels down the descending aorta to supply the lower body. Unlike in adults, the right ventricle contributes more than half of the fetal cardiac output. ${ }^{21}$

Obstruction of the proximal right outflow tract normally results in compensation by the left ventricle and preservation of fetal circulatory dynamics. However, obstruction of the distal ductus arteriosus will result in increased biventricular afterloads, diminished strokes volumes, increased central venous pressures, and eventually hydrops fetalis. Premature constriction of the distal ductus arteriosus as a result of maternal nonsteroidal anti-inflammatory drug exposure or congenital heart defects such as truncus arteriosus or tetralogy of Fallot have been associated with hydrops fetalis. ${ }^{22}$ Large thoracic space occupying lesions such as congenital cystic adenomatoid malformations, bronchopulmonary sequestrations, bronchogenic cysts, congenital lobar emphysema, and segmental bronchial atresia may also result in hydrops from direct cardiac compression. ${ }^{23}$ Less common intrathoracic tumors that have also been reported to cause hydrops fetalis include mediastinal teratomas, fibrosarcomas, lymphangiomas, and intrapericardial teratomas. ${ }^{24-29}$ In our case, we propose that multiple ganglioneuromas compressed the distal ductal and aortic arches as well as the proximal descending aorta, eventually leading to the development of $\mathrm{NIH}$ fetalis. To our knowledge, apart from neuroblastomas, no other neural crest tumors have previously been described perinatally.

Neural crest tumors are extremely difficult to definitively diagnose prenatally and most often require pathologic confirmation following delivery. Fénart et al first described the prenatal diagnosis of a neuroblastoma by ultrasound in 1983. ${ }^{30}$ Sonographically, neuroblastomas may appear cystic, solid, or of mixed echogenicity. ${ }^{31-36}$ Although most neuroblastomas diagnosed antenatally are adrenal in origin, thoracic neuroblastomas have rarely been reported as well. $^{37,38}$ In a review of 271 neonates with neuroblastomas, Isaacs Jr reported that six tumors were located within the mediastinum, three of which were detectable antenatally. ${ }^{39}$ Elevated catecholamine metabolites released from fetal neural crest tumors may cause maternal hypertension. Twenty-four-hour maternal urine assay or amniocentesis for fetal urinary catecholamine metabolites has been reported to aid in the prenatal diagnosis of neuroblastomas. ${ }^{40}$ Unfortunately, almost 60 to $70 \%$ of neuroblastomas diagnosed in the perinatal period are thought to be nonsecretory. ${ }^{41}$

Our case represents the first description of a thoracic ganglioneuroma diagnosed during the perinatal period. The differential diagnosis for fetal thoracic masses should, therefore, include the spectrum of neural crest tumors and the recognition that these tumors may cause cardiac outflow obstruction, fetal congestive heart failure, and eventually $\mathrm{NIH}$ fetalis.

\section{Disclosure}

No competing financial conflicts exist for any authorinvestigator.

\section{References}

1 Shetty PKBK, Gnana Prakash S, Shetty PK. Ganglioneuroma always a histopathological diagnosis. Online J Health Allied Scs. 2010; $9(4): 19$

2 Gary C, Robertson H, Ruiz B, Zuzukin V, Walvekar RR. Retropharyngeal ganglioneuroma presenting with neck stiffness: report of a case and review of literature. Skull Base 2010; 20(5):371-374

3 Aktüre E, Salamat MS, Korkmaz H, Baskaya MK. Ganglioneuroma of the sphenoid wing: a case report and literature review. Clin Neuropathol 2011;30(6):313-317

4 Kanthan R, Senger JL, Kanthan S. Three uncommon adrenal incidentalomas: a 13-year surgical pathology review. World J Surg Oncol 2012;10:64

5 Müller A, Förster G, Behrendt W, Kosmehl H. Headache as an unusual presenting symptom of retropharyngeal ganglioneuroma. Acta Otolaryngol 2002;122(5):565-568

6 Papso S, Bencat M. Ganglioneuroma in retropharyngeal location. Case report of a sixteen-month-old boy. Helv Paediatr Acta 1989; 43(4):303-305 
7 Preidler KW, Ranner G, Szolar D, Walch C, Anderhuber W. Retropharyngeal ganglioneuroma: ultrasound, CT and MRI findings in a 57-year-old patient. Eur J Radiol 1995;19(2):108-110

8 Preidler KW, Ranner G, Szolar D, Walch C, Anderhuber W. Ultrasonography, CT and MRI of retropharyngeal ganglioneuroma: a very rare neoplasm in adults. Neuroradiology 1996;38(4):378-380

9 Rabjerg M, Kolodziejczyk A. [A solitary ganglioneuroma occurring in the sigmoid colon]. Ugeskr Laeger 2012;174(39):2305-2306

10 Walch C, Anderhuber W, Preidler K, Humer U. Retro- and parapharyngeal ganglioneuroma. J Laryngol Otol 1996;110(1):87-90

11 Jain M, Shubha BS, Sethi S, Banga V, Bagga D. Retroperitoneal ganglioneuroma: report of a case diagnosed by fine-needle aspiration cytology, with review of the literature. Diagn Cytopathol 1999;21(3):194-196

12 Lonergan GJ, Schwab CM, Suarez ES, Carlson CL. Neuroblastoma, ganglioneuroblastoma, and ganglioneuroma: radiologic-pathologic correlation. Radiographics 2002;22(4):911-934

13 Hayes FA, Green AA, Rao BN. Clinical manifestations of ganglioneuroma. Cancer 1989;63(6):1211-1214

14 Gültekin M, Dursun P, Salman C, et al. Ganglioneuroma mimicking ovarian tumor: a report of a case and review of the ganglioneuromas. Arch Gynecol Obstet 2005;271(1):66-68

15 Rosai J, ed. Adrenal gland and other paraganglia. In: Ackerman's surgical pathology (8th ed.). St. Louis, MO: Mosby-Year Book; 1996:1015-1058

16 Kleihaus PCW, ed. WHO Classification of Tumors. In: Pathology and Genetics: Tumors of the Nervous system. Lyon, France: IARC press; 2000:96-98

17 Gentile S, Rainero I, Luda E, Pinessi L. Autonomic dysfunction associated with multiple pelvic ganglioneuromas. Acta Neurol Scand 2001;104(1):54-56

18 Bjellerup P, Theodorsson E, Kogner P. Somatostatin and vasoactive intestinal peptide (VIP) in neuroblastoma and ganglioneuroma: chromatographic characterisation and release during surgery. Eur J Cancer 1995;31A(4):481-485

19 Ostertun B, Harder T, Reetz KP. [Ganglioneuroma of the lesser pelvis]. Rofo 1987;147(1):93-94

20 Santo S, Mansour S, Thilaganathan B, et al. Prenatal diagnosis of non-immune hydrops fetalis: what do we tell the parents? Prenat Diagn 2011;31(2):186-195

21 Rasanen J, Wood DC, Weiner S, Ludomirski A, Huhta JC. Role of the pulmonary circulation in the distribution of human fetal cardiac output during the second half of pregnancy. Circulation 1996; 94(5):1068-1073

22 Harlass FE, Duff P, Brady K, Read J. Hydrops fetalis and premature closure of the ductus arteriosus: a review. Obstet Gynecol Surv 1989;44(7):541-543

23 Cass DL, Olutoye OO, Cassady CI, et al. Prenatal diagnosis and outcome of fetal lung masses. J Pediatr Surg 2011;46(2):292-298

24 Dolkart LA, Reimers FT, Kuonen CA. Intrathoracic congenital fibrosarcoma. A case report. J Reprod Med 1995;40(5):391-393
25 Froberg MK, Brown RE, Maylock J, Poling E. In utero development of a mediastinal teratoma: a second-trimester event. Prenat Diagn 1994;14(9):884-887

26 Kuller JA, Laifer SA, Martin JG, MacPherson TA, Mitre B, Hill LM. Unusual presentations of fetal teratoma. J Perinatol 1991;11(3): 294-296

27 Lindinger A, Boos R, Pistorius K, Limbach HG, Jesberger HJ, Hoffmann W. [Mediastinal cystic lymphangioma as a cause of hydrops fetalis]. Klin Padiatr 1992;204(2):118-122

28 Tollens T, Casselman F, Devlieger H, et al. Fetal cardiac tamponade due to an intrapericardial teratoma. Ann Thorac Surg 1998;66(2): 559-560

29 Weinraub Z, Gembruch U, Födisch HJ, Hansmann M. Intrauterine mediastinal teratoma associated with non-immune hydrops fetalis. Prenat Diagn 1989;9(5):369-372

30 Fénart D, Deville A, Donzeau M, Bruneton JN. [Retroperitoneal neuroblastoma diagnosed in utero. Apropos of 1 case]. J Radiol 1983;64(5):359-361

31 Ganick DJ, Kodroff MB, Marrow HG, Holbrook CT, Pories WJ. Thoracic neuroblastoma presenting as a cystic hygroma. Arch Dis Child 1988;63(10):1270-1271

32 Giulian BB, Chang CC, Yoss BS. Prenatal ultrasonographic diagnosis of fetal adrenal neuroblastoma. J Clin Ultrasound 1986;14(3): 225-227

33 Guin GH, Gilbert EF, Jones B. Incidental neuroblastoma in infants. Am J Clin Pathol 1969;51(1):126-136

34 Hendry GM. Cystic neuroblastoma of the adrenal gland-a potential source of error in ultrasonic diagnosis. Pediatr Radiol 1982; 12(4):204-206

35 Ho PT, Estroff JA, Kozakewich $\mathrm{H}$, et al. Prenatal detection of neuroblastoma: a ten-year experience from the Dana-Farber Cancer Institute and Children's Hospital. Pediatrics 1993;92(3): 358-364

36 Jennings RW, LaQuaglia MP, Leong K, Hendren WH, Adzick NS. Fetal neuroblastoma: prenatal diagnosis and natural history. J Pediatr Surg 1993;28(9):1168-1174

37 de Filippi G, Canestri G, Bosio U, Derchi LE, Coppi M. Thoracic neuroblastoma: antenatal demonstration in a case with unusual post-natal radiographic findings. Br J Radiol 1986;59(703): 704-706

38 Gorincour G, Dugougeat-Pilleul F, Bouvier R, et al. Prenatal presentation of cervical congenital neuroblastoma. Prenat Diagn 2003;23(8):690-693

39 Isaacs $\mathrm{H}$ Jr. Fetal and neonatal neuroblastoma: retrospective review of 271 cases. Fetal Pediatr Pathol 2007;26(4):177-184

40 Sebire NJ, Jauniaux E. Fetal and placental malignancies: prenatal diagnosis and management. Ultrasound Obstet Gynecol 2009; 33(2):235-244

41 Granata C, Fagnani AM, Gambini C, et al. Features and outcome of neuroblastoma detected before birth. J Pediatr Surg 2000;35(1): 88-91 